laboratories the capital expenditure in 1959-60 was $£ 9$ per student. The sub-committee concluded that the facilities provided for practical work were quite inadequate both in time and in accommodation. If practical work is to be given adequate time, science students must be propared either to devote more hours weekly to their training, or to have their training extended beyond the present university terms.

To overcome the inadequacy of laboratory accommodation, the report recommends the establishment of Science Teaching Centres in all universities, in the departments or institutes of education or elsewhere. These centres should have adequate laboratory accommodation, be organized by a director and have a panel of visiting school teachers. It is suggested that the establishment of such centres would help to meet the present need for refresher courses for established teachers and for part-time courses leading to a higher professional qualification, such as university diploma in the teaching of science. It is also recommended that the training course to be taken by all intending science teachers should pay adequate attention to general principles of education and to studies in the philosophy, method and social consequences of science. School practice should comprise a complete school term and only in schools where adequate supervision and help are provided. There should be more liaison botween school supervisor and departmental tutor both at the personal and professional level. Departments of Education should be asked to consider the merits of continuous assessment and the time spent on method and practical work, and Department of Education staffs and local branches of the Science Masters' Association and the Association of Women Science Torchers should ensure that effective and continuous contact exists between each Department and the science teachers in its area. Conditions in Scotland are regarded as in many ways in advanct) of those in England and Wales; but there is considerable dissatisfaction with the student/staff ratio and the inadequate provision of rooms and equipment in the: colleges.

\title{
CHALLENGES OF SCIENCE IN SOUTH AFRICA
}

$\mathrm{I}^{\mathrm{N}}$ his presidential address to the Diamond Jubilee Congress of the South African Association for the Advancement of Science at Cape Town, July 1962, Prof. J. P. Duminy, under the title "The Challenges of Science To-day", discussed more particularly the universal shortage of manpower which, he suggested, arises out of the unplanned and unexpected advances in technology in the past decade--out of what can be deseribed as an explosion in the field of scientific knowledge. But for this, South Africa might have been able to cope with its internal post-war domands for trained personnel. However, extreme difficulty is now being experienced in attracting mon from abroad to institutions there and in training South Africans in their own universities to meet the manpower needs.

South Africa has never enjoyed the means of providing facilities at its universities necessary for training men to the levels of teaching and research in science and tochnology which are essential. Many of those who go overseas in order to obtain qualifications nevor return. Some mobility and interchange are desirable, but for soveral years the movement has been consistently one way. Investigations into the sources of trained manpower have shown that the universities will be powerless to play their full part unless the interest of youth is aroused and larger. numbers are stimulated to take up careers in science and technology. The Manpower Development Foundation. created under the auspices of the Association and in collaboration with the Federation of Science Teachers' Associations, seeks to improve the teaching of science in the schools. Publication of a periodical dealing with methods and material for teaching physies, chemistry. mathematics and biology is planned. A significant contribution is also being made by the Permanont Exhibition of Modern Science.

In conclusion, Prof. Dunning, observing that seience is not independent of philosophy and that philosophical thinking is not incompatible with scientific concepts. urged that the schism between tho humanities and the sciences must be healed and science enabled to make it: full contribution in our thinking about the realities of human existence and the rolations betweon human heings.

\section{PROGRESS AND INNOVATION IN SCIENTIFIC RESEARCH}

N his Peter Le Neve Lecture to the Royal Society of
Arts on January 9, on "Progress and Innovation",
Mr. J. C. Duckworth, managing director of the National
Rosearch Development Corporation, said that in these days
of the large development and design team it is often
difficult to decide what is truly invention and what is
purely the logical outcome of applied research or develop-
ment work. The actual invention of a new device or
process can occur very soon after the requisite knowledge
is available, and indeed almost as part of the process of
acquiring it, or the invention may come long after the
necessary knowledge is available. On the other hand, the
inventor may be too far ahead of the 'frontiors of know-
ledge' for his ideas to be practicable.
Mr. Duckworth suggested that over the past two
conturies the nature of invention has changed. The
principle of designing new equipment to meet a need is
now well established and such design should not be con-
sidered invention unless it incorporates some novel
feature or concept beyond that which the ordinary design engineer can be expected to provide. The fact that ideas such as the hovercraft can be conceived by an individual should encourage those who believe that inventions may be possible by those outside the large resoarch anit development teams. Moreover, it is probable that individual inventors will have most success where a combination of different disciplines is required to produce the new idea.

After emphasizing that an invention only makes its impact if the economic and social climate is ready for its acceptance, in addition to the need for technical development to reach a sufficiently advancod stage, Mr. Duckworth observed that within the team the croative genius of invention is still required to make more than humdrum progress. The National Research Development Corpora. tion was set up partly due to the belief that inventions of obvious merit were being suppressed because their development jeopardized the position of established products; however, the Corporation found no reliables evidence of this. Development contracts involve an appreciable proportion of the effort and expenditure of 
the Corporation which operates its development activities in an area in which it is particularly difficult for the individual inventor to succeed. In many other industrialized nations industry is more receptive to new ideas and will generally take up innovations more quickly and enthusiastically than in Britain, or is prepared to take greater risks where final commercial viability is less easy to assess. The Corporation generally becomes directly involved where the technical possibility is more in doubt, the commercial prospects are difficult to assess, or where it appears that there may be a benefit to the community as a whole, and where the benefit to one branch of industry may be marginal.

There is no doubt that the individual inventor now has a difficult task and that in the scientific field the inventor is increasingly a highly qualified man working with adequate resources. True inventiveness should always be encouraged and in spite of the fact that the lone inventor now has a smaller chance of making significant scientific advances, if he does succeed in doing so he has a better chance than ever before of getting his ideas adopted, followed by fair treatment and financial reward.

\section{THE EUROPEAN ORGANIZATION FOR NUCLEAR RESEARCH}

$\mathrm{T}$ HE seventh annual report of the European Organization for Nuclear Research (CERN) * covers the period to the end of 1961 and gives a detailed account of the activities of the Organization during a year which Prof. V. F. Weisskopf, the director-general of the Organization, describes in his introduction to the report as "an exporimental year". It was the first year in which the research programme got into something approaching its full stride and in which tentative solutions wore tried out to the problems of internal organization, of the shaping and management of the programme itself, and of relationships with other research organizations and research physicists.

The staff on December 31, 1961, numbered 1,091, of whom 187 wore scientists and engineers, 573 technicians, 149 administrative and 182 ancillary members. They were organized in twelve divisions under a directorate of three and the director-general. The total expenditure during 1961 amounted to $70 \cdot 2$ million Swiss franes, of which $36 \cdot 2$ million was devoted to capital expenditure, mainly on buildings and on the accelerators and experimental equipment; 8.4 million on general expenditure; and $25 \cdot 6$ million on staff salaries and expenses.

The mean intensity of the proton synchrotron remained at about $2.5 \times 10^{11}$ protons/pulse with a trapping efficiency of 50 per cent. The machine time allocated to nuclear physics experiments increased by about 50 per cent, from $62 \mathrm{~h}$ per week during January to $93 \mathrm{~h}$ per week during October. About 15 per cent of the total machine time was lost through various breakdowns. The commissioning during August of a new experimental hall (North Hall) made room for two extra beams to be set up, making a total of five beams in uso round the machine at the end of 1961 .

Two CERN-dosigned electrostatic separators came into operation during the year. A voltage of $750 \mathrm{kV}$ could be held over a gap of $14 \mathrm{~cm}$ in a 3-4 GoV/c. antiproton beam and of $500 \mathrm{kV}$ over a gap of $8.5 \mathrm{~cm}$ in a $1.5 \mathrm{GoV} / \mathrm{c.K}$ beam. Other new separators, including a radio-frequency separator, are under construction.

The research performed by members of the Nucloar Physics Division with the proton synchrotron was very fruitful. In the section of the report dealing with the activities of this Division, 16 experiments with the proton synchrotron and 11 with the synchro-cyclotron are describod in some dotail. For the proton synchrotron these include elastic and near-elastic scattering of protons on protons; total cross-section measurements of highenergy pions on hydrogen; strange particle physics; the measurement of resonances in the two-pion system using a spark chamber; the determination of the lifetime of the neutral pion, about $2 \times 10^{-16} \mathrm{sec}$; muon electron scattering; and the search for magnetic monopoles. Long experiments were performed with the help of two large French bubble chambers. 300,000 photographs were

* CeERN, European Organization for Nuclear Research. Annual Report for 1961. Pp. 153. (Geneva: CERN, 1962.) taken with the 81-cm Saclay hydrogen bubble chamber in a beam of slow antiprotons and 80,000 pictures by the same chamber in a fast $(3 \cdot 0-4 \cdot 0 \mathrm{GoV})$ antiproton beam. (It was in the latter series of pictures that for the first time, early in 1962, a charged anti- $X i$ particle was found.) Interesting results were also obtained in the study of photo. graphs taken with the 30 -cm hydrogen bubble chamber.

The experiments with the synchro-cyclotron included the outstanding experiment to measure the magnetic moment of the muon to an accuracy of 1 in 200,000 , thus establishing that the muon is accurately described as a Dirac particle with no interaction other than the electromagnetic and the weak kinds--that is, that it bohaves exactly as a heavy electron. During 1961 an experiment on the scattering of negative $\mu$-mesons on $C$ was started, and the reaction $\mu^{-}+p \rightarrow n+\nu$ was investigated directly without nuclear complications in the Italian $20-\mathrm{cm}$ hydrogen bubble chamber. The energies of $\mu$-mesic X-ray transitions $(2 p-1 s$ and $3 d-2 p)$ were measured for many nuclei throughout the Periodic Table, and the search for the neutrino-less conversion of a muon into an electron using an improved $\mu^{-}$beam intensity and a spark chamber has continued.

Using a modular system of construction, the Electronies Workshop has produced a comprehensive range of transistorized nucleonic instruments for use in the nuclear physics experiments. The range includes a fast triple coincidence circuit, fast discriminator, 5-way splits, djlays and triggers, 100-Mc/s pre-scaler, fast-pulse amplifier with a gain of 10 and rise of $2 \mathrm{nsec}$, and pulse burst generators. Some work has been initiated in the field of image intensifiers and scintillation chambers.

During the year under review it became clear that more attention would have to be given to data handling and analysis, and that more and more machine time would be required from computers with faster operation and larger memories. The introduction of a 709 computor has greatly increased the computing facilities; but the absence of a link between the 709 and the Mercury computer has been the main bottleneck. A number of general-purpose programmes have been added and an improved compilor has been introduced to simplify tho testing of Autocode programmes.

The staff of the Theoretical Study Division at the end of 1961 comprised ten scientists, one computer-programmer and two secretaries. In addition. about thirty theoreticians under the CERN and Ford Foundation fellowship programmes were working at any one time in the Division. Various problems characteristic of the very-high-energy region opened up by the CERN proton synchrotron were given special attention. Near-elastic scattering of nucleons on nuclei, inelastic nucleon-nucleon scattering with very small energy loss, and the interactions of high-energy neutrinos with complex nuclei, were the main subjects of study. A variety of problems relating to the physics of pions and nucleons and of strange particles have also been investigated. The Theoretical 